Website: http://journal.umy.ac.id/index.php/mrs

DOI: $10.18196 / \mathrm{jmmr} .5120$.

\title{
Pengaruh Mutu Pelayanan Dokter Terhadap Loyalitas Pasien di Rumah Sakit PKU Muhammadiyah Bantul
}

\author{
Tati Fatmawati $^{1 *} \&$ Susanto $^{2}$ \\ *Penulis Korespondensi:fatma.azzaria@gmail.com \\ ${ }^{1}$ Rumah Sakit PKU Muhammadiyah Bantul \\ ${ }^{2}$ Magister Manajemen Rumah Sakit Universitas Muhammadiyah Yogyakarta

\begin{tabular}{|c|c|}
\hline INDEXING & A BS STRACT \\
\hline Keywords: & Doctors is one of the main resources that provide services directly to patients. Doctor's quality \\
\hline Doctor quality service, & service at the hospital will build the patient's attitudes and trust related to the reuse of hospital \\
\hline patient, & services. Loyal patients will have linkages with hospital and enable the ralization of long term \\
\hline general polyclinic & relationship. Purpose knowing the influence of technical skills, interpersonal relationship, \\
\hline & availability of information and the involvement of patient to the patient loyalty at general polyclinic \\
\hline & in RS PKU Muhammadiyah Bantul. This research is an analytic inferential with cross sectional \\
\hline & approaches. Populations of this research are olden patient in general polyclinic at $R S P K U$ \\
\hline & Muhammadiyah Bantul. Sampling technique is purposive sampling with number of samples are 87 \\
\hline & persons. Collecting data using kuesioner. Data analysis with multiple regretion analysis. Technical \\
\hline & $\begin{array}{l}\text { skills, interpersonal relationship, availability of information, and patent involvement have an } \\
\text { influence to the patient loyalty in general polyclinic in } R S P K U \text { Muhammadiyah Bantul. }\end{array}$ \\
\hline
\end{tabular}

(C) 2016 JMMR. All rights reserved

Article history: received 12 April 2016; revised 22 Mei 2016; accepted 17 Juni 2016

\section{PENDAHULUAN}

Perkembangan sektor pelayanan jasa kesehatan menyebabkan semakin ketatnya persaingan pada pelayanan jasa rumah sakit. Rumah sakit saling berlomba untuk memberikan pelayanan kesehatan sesuai dengan tuntutan masyarakat. ${ }^{1}$

Layanan kesehatan yang bermutu adalah suatu layanan kesehatan yang dibutuhkan masyarakat yang sangat ditentukan oleh profesi layanan kesehatan yang mampu memberikan pelayanan kesehatan sesuai dengan kebutuhan masyarakat sebagai pengguna layanan kesehatan dengan harga yang terjangkau. Keberhasilan rumah sakit bukan dilihat dari biaya, melainkan dari mutu. Apabila mutu dapat dicapai maka pelayanan akan terjamin maka hasilnya dapat menciptakan kepuasan pelanggan dan mendatangkan keuntungan bagi rumah sakit. ${ }^{2}$

Ariadi dalam penelitiannya diperoleh hasil faktor dimensi mutu terbukti berhubungan secara signifikan dengan persepsi pasien mengenai mutu pelayanan dokter rawat jalan, dan hasil analisis multivariat membuktikan bahwa persepsi pasien tentang mutu pelayanan dokter rawat jalan dipengaruhi oleh hubungan interpersonal $(\mathrm{p}<0,05)$, ketersediaan informasi $(p<0,05)$ dan keterlibatan pasien dalam pengobatan $(\mathrm{p}<0,05){ }^{3}$

Mutu pelayanan yang diberikan oleh dokter di poliklinik umum rawat jalan sangat menentukan loyalitas pasien. Pasien akan cenderung menjadi loyal karena percaya kepada kemampuan dokter dalam mengatasi permasalahan kesehatan yang dialami oleh pasien. $^{2}$

\section{METODE PENELITIAN}

Penelitian ini menggunakan desain penelitian analitik inferensial yaitu penelitian yang bertujuan untuk menganalisis data sekaligus membuktikan hipotesis penelitian yang hasilnya digeneralisasikan pada populasi penelitian.4 Pendekatan waktu yang digunakan adalah cross sectional yaitu variabelvariabel yang termasuk fenomena, faktor resiko, dan variabel yang termasuk efek diobservasi sekaligus pada waktu yang sama.5 
Subyek penelitian adalah pasien lama di Poliklinik umum instalasi rawat jalan RS PKU Muhammadiyah Bantul. Teknik pengambilan sampel dalam penelitian ini adalah purposive sampling dengan jumlah sampel sebanyak 100 orang. Penelitian ini dilakukan di RS PKU Muhammadiyah Bantul. Instrumen penelitian menggunakan kuesioner. Analisis data menggunakan analisis regresi linier berganda.

\section{HASIL DAN PEMBAHASAN}

\section{Karakteristik Responden}

Tabel 1. Deskripsi Karakteristik Responden pada Pasien di Poliklinik Umum Instalasi Rawat Jalan RS PKU Muhammadiyah Bantul

\begin{tabular}{ccc}
\hline Karakteristik & Fekuensi & $\begin{array}{c}\text { Persentase } \\
\text { (\%) }\end{array}$ \\
\hline Umur & & \\
18-35 tahun & 50 & 50,0 \\
$36-55$ tahun & 40 & 40,0 \\
$>55$ tahun & 10 & 10,0 \\
Pendidikan & & \\
SD & 17 & 17,0 \\
SMP & 26 & 26,0 \\
SMA & 42 & 42,0 \\
Perguruan Tinggi & 15 & 15,0 \\
Pekerjaan & & \\
Wiraswasta & 28 & 28,0 \\
Swasta & 18 & 18,0 \\
PNS & 6 & 6,0 \\
Mahasiswa & 20 & 20,0 \\
Petani & 6 & 6,0 \\
Buruh & 6 & 6,0 \\
IRT & 16 & 16,0 \\
Frekuensi & & \\
Pemanfaatan & & \\
Pelayanan & & 100,0 \\
1 & 21 & 21,0 \\
2 & 35 & 35,0 \\
3 & 29 & 29,0 \\
4 & 14 & 14,0 \\
$\geq 5$ & 1 &
\end{tabular}

Sumber: Data primer diolah 2015

Hasil analisis deskriptif karakteristik responden berdasarkan umur diketahui sebagian besar responden berumur $18-35$ tahun yaitu sebanyak 50 orang (50\%). Karakteristik berdasarkan pendidikan diketahui sebagian besar berpendidikan SMA yaitu sebanyak 42 orang (42\%). Karakteristik responden menurut pekerjaan diketahui sebagian besar responden adalah wiraswasta yaitu sebanyak 28 orang (28\%). Karakteristik berdasarkan frekuensi pemanfaatan pelayanan rawat jalan diketahui sebagian besar responden telah memanfaatkan pelayanan kesehatan sebanyak 2 kali yaitu sebanyak 35 orang (35\%).

\section{Hasil Analisis Data Penelitian}

\section{Deskripsi Data Penelitian}

Tabel 2. Hasil Analisis Deskriptif Data Variabel Penelitian

\begin{tabular}{lcccc}
\hline \multicolumn{1}{c}{ Data } & Min & Max & Mean & $\begin{array}{l}\text { Std. } \\
\text { Dev }\end{array}$ \\
\hline $\begin{array}{l}\text { Kemampuan } \\
\text { Teknis }\end{array}$ & 30,00 & 44,00 & 38,84 & 2,62 \\
$\begin{array}{l}\text { Hubungan } \\
\text { Interpersonal }\end{array}$ & 33,00 & 50,00 & 45,43 & 3,53 \\
$\begin{array}{l}\text { Ketersediaan } \\
\text { Informasi }\end{array}$ & 28,00 & 50,00 & 41,84 & 4,17 \\
$\begin{array}{l}\text { Keterlibatan } \\
\text { Pasien }\end{array}$ & 22,00 & 45,00 & 35,41 & 3,95 \\
Loyalitas & 30,00 & 50,00 & 40,14 & 5,93 \\
\hline Sumber: Data primer diolah 2015 & & &
\end{tabular}

\section{Kemampuan Teknis}

Hasil analisis data kemampuan teknis diperoleh skor terendah adalah 30,00 dan skor tertinggi adalah 44,00. Hasil analisis statistik deskriptif diperoleh rerata $(\mathrm{M})=38,84$; Simpangan Baku $(\mathrm{SB})=2,62$. Nilai rerata hitung kemampuan teknis sebesar 38,48 apabila dibandingkan dengan nilai rerata ideal sebesar 27,00, menunjukkan angka yang lebih besar. Artinya kemampuan teknis dokter telah dinilai baik oleh pasien.

\section{Hubungan Interpersonal}

Hasil analisis data hubungan interpersonal diperoleh skor terendah adalah 33,00 dan skor tertinggi adalah 50,00. Hasil analisis statistik deskriptif diperoleh rerata $(M)=45,43$; Simpangan Baku $(S B)=$ 3,53. Nilai rerata hitung hubungan interpersonal sebesar 45,43 apabila dibandingkan dengan nilai rerata ideal sebesar 30,00, menunjukkan angka yang lebih besar. Artinya hubungan interpersonal yang dilakukan dokter telah dinilai baik oleh pasien. 


\section{Ketersediaan Informasi}

Hasil analisis data ketersediaan informasi diperoleh skor terendah adalah 28,00 dan skor tertinggi adalah 50,00. Hasil analisis statistik deskriptif diperoleh rerata $(\mathrm{M})=41,84$; Simpangan Baku $(\mathrm{SB})=$ 4,17 . Nilai rerata hitung ketersediaan informasi sebesar 41,84 apabila dibandingkan dengan nilai rerata ideal sebesar 30,00, menunjukkan angka yang lebih besar. Artinya ketersediaan informasi telah dinilai baik oleh pasien.

\section{Keterlibatan Pasien}

Hasil analisis data keterlibatan pasien diperoleh skor terendah adalah 22,00 dan skor tertinggi adalah 45,00 . Hasil analisis statistik deskriptif diperoleh rerata $(M)=35,41$; Simpangan Baku $(S B)=3,95$. Nilai rerata hitung keterlibatan pasien sebesar 35,41 apabila dibandingkan dengan nilai rerata ideal sebesar 27,00, menunjukkan angka yang lebih besar. Artinya keterlibatan dokter dengan pasien telah dinilai baik oleh pasien.

\section{Loyalitas}

Hasil analisis data loyalitas diperoleh skor terendah adalah 30,00 dan skor tertinggi adalah 50,00. Hasil analisis statistik deskriptif diperoleh rerata $(\mathrm{M})=$ 40,14; Simpangan Baku $(\mathrm{SB})=5,93$. Nilai rerata hitung loyalitas sebesar 40,41 apabila dibandingkan dengan nilai rerata ideal sebesar 30,00, menunjukkan angka yang lebih besar. Artinya kemampuan loyalitas pasien dalam kategori tinggi.

\section{Pengujian Hipotesis}

\section{Tabel 4. Hasil Analisis Regresi Sederhana}

\begin{tabular}{|c|c|c|c|c|c|c|}
\hline \multicolumn{7}{|c|}{ Coefficients } \\
\hline \multirow[b]{2}{*}{ Model } & & \multicolumn{2}{|c|}{$\begin{array}{c}\text { Unstandardized } \\
\text { Coefficients }\end{array}$} & \multirow{2}{*}{\begin{tabular}{|c|}
$\begin{array}{l}\text { Standardized } \\
\text { Coefficients }\end{array}$ \\
Beta \\
\end{tabular}} & \multirow[b]{2}{*}{$t$} & \multirow[b]{2}{*}{ Sig. } \\
\hline & & $B$ & Std. Enor & & & \\
\hline$T$ & (Constant) & .31 .522 & 4.410 & & .7 .148 & .000 \\
\hline & Kemampuan teknis & 444 & .144 & .196 & 3.095 & .003 \\
\hline & Hubungan interperso & 352 & 122 & .209 & 2.877 & .005 \\
\hline & Ketersediaan inform & 331 & .094 & .233 & 3.527 & .001 \\
\hline & Keterlbatan pasien & 694 & 086 & 462 & 8.056 & .000 \\
\hline
\end{tabular}

Sumber: Data primer diolah 2015

\section{Koefisien Determinasi (R2)}

Tabel 5. Nilai Koefisien Determinasi

\begin{tabular}{ccccc}
\hline Modal & R & R Square & Adjusted R Square & Error Of The Estimate \\
\hline 1 & $.886^{\mathrm{a}}$ & .785 & .776 & 2.81091 \\
\hline Sumber: Data primer diolah 2015 & & & \\
\hline
\end{tabular}

Sumber: Data primer diolah 2015

\section{Uji F}

\section{Tabel 4. Hasil Uji F}

Hasil analisis regresi ganda diperoleh nilai $\mathrm{F}$ hitung sebesar 86,741 dengan signifikansi sebesar 0,000 . Oleh karena nilai signifikansi tersebut lebih kecil dari 0,05 $(\mathrm{p}<0,05)$, maka hipotesis diterima. Artinya kemampuan teknis, hubungan interpersonal, ketersediaan informasi dan keterlibatan pasien secara simultan berpengaruh signifikan terhadap loyalitas pasien di Poliklinik umum instalasi rawat jalan RS PKU Muhammadiyah Bantul.

\section{Uji t (secara parsial)}

\section{Kemampuan Teknis}

Hasil statistik uji t pada variabel kemampuan teknis diperoleh nilai $\mathrm{t}$ hitung sebesar 3,095 dengan tingkat signifikansi 0,003 . Oleh karena nilai signifikansi lebih kecil dari $0,05 \quad(\mathrm{p}<0,05)$, maka hipotesis diterima. Artinya terdapat pengaruh signifikan kemampuan teknis terhadap loyalitas. Dapat disimpulkan kemampuan teknis secara parsial 
berpengaruh signifikan terhadap loyalitas pasien di Poliklinik umum instalasi rawat jalan RS PKU Muhammadiyah Bantul.

\section{Hubungan Interpersonal}

Hasil statistik uji $\mathrm{t}$ pada variabel hubungan interpersonal diperoleh nilai $\mathrm{t}$ hitung sebesar 2,877 dengan tingkat signifikansi 0,005 . Oleh karena nilai signifikansi lebih kecil dari 0,05 ( $<<0,05)$, maka hipotesis diterima. Artinya terdapat pengaruh signifikan hubungan interpersonal terhadap loyalitas. Dapat disimpulkan hubungan interpersonal secara parsial berpengaruh signifikan terhadap loyalitas pasien di Poliklinik umum instalasi rawat jalan RS PKU Muhammadiyah Bantul.

\section{Ketersediaan Informasi}

Hasil statistik uji t pada variabel ketersediaan informasi diperoleh nilai t hitung sebesar 3,527 dengan tingkat signifikansi 0,001 . Oleh karena nilai signifikansi lebih kecil dari $0,05 \quad(\mathrm{p}<0,05)$, maka hipotesis diterima. Artinya terdapat pengaruh signifikan ketersediaan informasi terhadap loyalitas. Dapat disimpulkan ketersediaan secara parsial berpengaruh signifikan terhadap loyalitas pasien di Poliklinik umum instalasi rawat jalan RS PKU Muhammadiyah Bantul.

\section{Keterlibatan Pasien}

Hasil statistik uji t pada variabel keterlibatan pasien diperoleh nilai t hitung sebesar 8,056 dengan tingkat signifikansi 0,000 . Oleh karena nilai signifikansi lebih kecil dari $0,05 \quad(\mathrm{p}<0,05)$, maka hipotesis diterima. Artinya terdapat pengaruh signifikan keterlibatan pasien terhadap loyalitas. Dapat disimpulkan keterlibatan pasien secara parsial berpengaruh signifikan terhadap loyalitas pasien di Poliklinik umum instalasi rawat jalan RS PKU Muhammadiyah Bantul.

\section{Pembahasan}

Pengaruh mutu pelayanan dokter pada dimensi keterampilan teknis, hubungan interpersonal,

\section{ketersediaan informasi dan keterlibatan pasien terhadap loyalitas pasien}

Hasil penelitian diketahui terdapat pengaruh mutu pelayanan dokter pada dimensi keterampilan teknis, hubungan interpersonal, ketersediaan informasi dan keterlibatan pasien secara bersama-sama terhadap loyalitas pasien di Poliklinik Umum Instalasi Rawat Jalan di RS PKU Muhammadiyah Bantul. Dibuktikan dengan hasil analisis regresi ganda diperoleh nilai $\mathrm{F}$ hitung sebesar 86,741 dengan signifikansi sebesar $0,000(\mathrm{p}<0,05)$. Artinya kemampuan teknis, hubungan interpersonal, ketersediaan informasi dan keterlibatan pasien merupakan komponen penting yang secara signifikan berpengaruh terhadap loyalitas pasien.

Berdasarkan hasil penelitian diketahui nilai koefesien regresi dari seluruh variabel penelitian adalah positif. faktor kemampuan teknis, hubungan interpersonal, ketersediaan informasi dan keterlibatan pasien mempunyai pengaruh yang positif terhadap loyalitas. Artinya semakin baik faktor-faktor tersebut maka akan semakin tinggi loyalitas pasien terhadap rumah sakit. Berdasarkan hasil jawaban kuesioner responden diketahui nilai rerata hitung loyalitas sebesar 40,41 apabila dibandingkan dengan nilai rerata ideal sebesar 30,00, menunjukkan angka yang lebih besar. Artinya kemampuan loyalitas pasien dalam kategori tinggi.

Loyalitas pasien terwujud dari terpenuhinya harapan pasien terhadap pelayanan yang ada di rumah sakit. Bagi pasien poliklinik umum yang tidak menjalani rawat inap di rumah sakit, mutu pelayanan dokter merupakan hal yang paling utama dipertimbangkan dalam pemilihan pelayanan kesehatan di rumah sakit. Hasil penelitian ini membuktikan bahwa mutu pelayanan dokter pada dimensi keterampilan teknis, hubungan interpersonal, ketersediaan informasi dan keterlibatan pasien berpengaruh terhadap terwujudnya loyalitas pasien. Kontribusi mutu pelayanan dokter pada dimensi keterampilan teknis, hubungan interpersonal, ketersediaan informasi dan keterlibatan pasien terhadap loyalitas pasien sebesar 77,6\%, sedangkan sisanya sebesar $22,4 \%$ dipengaruhi oleh faktor lain yang tidak diteliti dalam penelitian ini.

Mutu pelayanan dokter menjadi komponen yang sangat penting untuk diperhatikan dalam pelayanan kesehatan pasien umum. Terpenuhinya dimensi mutu 
pelayanan dokter mencakup keterampilan teknis, hubungan interpersonal, ketersediaan informasi dan keterlibatan pasien akan membuat pasien menjadi loyal untuk memanfaatkan pelayanan jasa kesehatan di rumah sakit. $^{7}$

Didukung teori disebutkan bahwa mutu pelayanan dokter menjadi kunci terwujudnya loyalitas pasien, dimana pasien akan cenderung menjadi loyal karena percaya kepada kemampuan dokter dalam mengatasi permasalahan kesehatan yang dialami oleh pasien. $^{2}$

Pengaruh mutu pelayanan dokter pada dimensi keterampilan teknis terhadap loyalitas pasien

Hasil penelitian membuktikan mutu pelayanan dokter pada dimensi keterampilan teknis berpengaruh signifikan terhadap loyalitas pasien. Dibuktikan dengan analisis regresi ganda didapatkan nilai diperoleh nilai t hitung sebesar 3,095 dengan tingkat signifikansi $0,003 \quad(\mathrm{p}<0,05)$. Artinya keterampilan teknis dokter dalam memberikan pelayanan kepada pasien berpengaruh terhadap loyalitas pasien di Poliklinik Umum Instalasi Rawat Jalan di RS PKU Muhammadiyah Bantul.

Berdasarkan hasil analisis diketahui keterampilan dokter meliputi pengetahuan dokter, ketepatan diagnosis dan keberhasil pengobatan dalam kategori baik. Hasil analisis didapatkan nilai rerata hitung kemampuan teknis sebesar 38,48 apabila dibandingkan dengan nilai rerata ideal sebesar 27,00, menunjukkan angka yang lebih besar. Artinya kemampuan teknis dokter telah dinilai baik oleh pasien.

Keterampilan teknis dokter yang telah sesuai harapan membuat pasien menjadi loyal terhadap rumah sakit sehingga menumbuhkan minat untuk datang kembali berobat di rumah sakit.

Hasil penelitian ini didukung penelitian sebelumnya diperoleh hasil penelitian terdapat pengaruh signifikan mutu pelayanan dokter rumah sakit Marmara terhadap kepuasan dan loyalitas pasien. ${ }^{5}$ Kesamaan hasil penelitian ini dengan penelitian sebelumnya menunjukkan bahwa kompetensi teknis dokter merupakan komponen penting dalam mencapai loyalitas pasien terhadap rumah sakit. Kompetensi teknis dokter menjadi bagian dari mutu pelayanan kesehatan yang harus diutamakan di rumah sakit guna mendapatkan loyalitas dari pasien. Didukung teori, disebutkan bahwa kompetensi teknis dokter sangat menentukan pelayanan kesehatan yang diberikan pada pasien, sehingga dapat meningkatkan kepuasan sekaligus membentuk loyalitas terhadap dokter dan rumah sakit. $^{2}$

\section{Pengaruh mutu pelayanan dokter pada dimensi hubungan interpersonal terhadap loyalitas pasien}

Hasil penelitian diketahui terdapat pengaruh mutu pelayanan dokter pada dimensi hubungan interpersonal terhadap loyalitas pasien di Poliklinik Umum Instalasi Rawat Jalan di RS PKU Muhammadiyah Bantul. Dibuktikan dengan hasil analisis regresi berganda didapatkan nilai $\mathrm{t}$ hitung sebesar 2,877 dengan tingkat signifikansi 0,005 $(\mathrm{p}<0,05)$. Artinya hubungan interpersonal menjadi faktor yang signifikan berpengaruh terhadap loyalitas pasien.

Pasien akan merasa nyaman dilayani oleh dokter yang mampu membangun hubungan interpersonal yang baik dengan pasien. Adanya rasa nyaman maka akan membuat pasien senang ditangani oleh dokter yang bersangkutan dan tidak segan untuk datang kembali pada dokter yang sama untuk berobat saat mengalami gangguan kesehatan.

Berdasarkan hasil penelitian diketahui hubungan interpersonal dokter di RS PKU Muhammadiyah Bantul sudah dilakukan dengan baik. Berdasarkan hasil penilaian responden didapatkan nilai rerata hitung hubungan interpersonal sebesar 45,43 apabila dibandingkan dengan nilai rerata ideal sebesar 30,00, menunjukkan angka yang lebih besar. Artinya hubungan interpersonal yang dilakukan dokter telah dinilai baik oleh pasien.

Hubungan interpersonal dapat mempengaruhi loyalitas dapat dijelaskan karena saat dokter mampu menjalin hubungan interpersonal yang baik dengan pasien maka pasien akan merasa nyaman, diperhatikan, dipedulikan sehingga percaya untuk ditangani oleh dokter yang bersangkutan. Rasa nyaman dan percaya pasien yang terbangun dari hasil hubungan interpersonal membuat pasien tidak merasa ragu untuk datang kembali pada dokter yang sama saat mengalami masalah kesehatan. Rumah sakit yang mampu memberikan pelayanan yang bermutu tinggi di mata pasien akan membentuk hubungan antar personal yang 
baik antara kedua belah pihak akan dan sangat mempengaruhi tingkat loyalitas pasien. ${ }^{2}$

Hasil penelitian ini didukung penelitian sebelumnya, didapatkan hasil penelitian interaksi personal berpengaruh terhadap intensi loyalitas pelanggan.6 Didukung teori yang menyebutkan hubungan interpersonal dokter dengan pasien akan membentuk suatu ikatan yang membuat pasien merasa nyaman sehingga pasien tidak segan untuk datang kembali berobat pada dokter yang telah melayaninya dengan baik. $^{2}$

\section{Pengaruh mutu pelayanan dokter pada dimensi ketersediaan informasi terhadap loyalitas pasien}

Hasil analisis data penelitian didapatkan hasil terdapat pengaruh mutu pelayanan dokter pada dimensi ketersediaan informasi terhadap loyalitas pasien di Poliklinik Umum Instalasi Rawat Jalan di RS PKU Muhammadiyah Bantul. Dibuktikan dengan hasil analisis regresi berganda didapatkan nilai $\mathrm{t}$ hitung sebesar 3,527 dengan tingkat signifikansi 0,001 $(p<0,05)$. Artinya ketersediaan informasi merupakan komponen yang secara signifikan mempengaruhi terwujudnya loyalitas pasien.

Ketersediaan informasi yang diberikan oleh dokter di RS PKU Muhammadiyah Bantul telah memuaskan oleh pasien. Hasil penelitian didapatkan nilai rerata hitung ketersediaan informasi sebesar 41,84 apabila dibandingkan dengan nilai rerata ideal sebesar 30,00 , menunjukkan angka yang lebih besar. Artinya ketersediaan informasi yang dilakukan oleh dokter di RS PKU Muhammadiyah Bantul telah dinilai baik oleh pasien.

Ketersediaan informasi mampu mempengaruhi loyalitas pasien dapat dijelaskan karena pasien yang merasa puas dengan ketersediaan informasi yang diberikan oleh dokter maka akan senang dan merasa nyaman dilayani oleh dokter tersebut. Pasien yang puas, senang dan nyaman maka cenderung akan kembali lagi pada dokter yang sama saat mengalami masalah kesehatan. Tahap selanjutnya pasien untuk melakukan pemakaian ulang jasa layanan kesehatan di rumah sakit. Kemampuan dokter dalam menyampaikan informasi membuat pasien merasa senang dan tidak segan untuk kembali memeriksakan diri pada dokter di rumah sakit tersebut. ${ }^{2}$
Hasil penelitian ini didukung oleh penelitian sebelumnya diperoleh hasil faktor dimensi mutu ketersediaan informasi terbukti berhubungan secara signifikan dengan persepsi pasien mengenai mutu pelayanan dokter rawat jalan. ${ }^{3}$ Dokter yang mampu menyediakan dan memberikan informasi secara jelas dan terperinci berkenaan dengan pengobatan yang dijalani pasien maka akan memuaskan pasien, yang pada tahap selanjutnya akan menarik minat pelanggan untuk menggunakan kembali saat membutuhkan layanan jasa yang sama.

\section{Pengaruh mutu pelayanan dokter pada dimensi keterlibatan pasien terhadap loyalitas pasien}

Hasil penelitian diketahui terdapat pengaruh mutu pelayanan dokter pada dimensi keterlibatan pasien terhadap loyalitas pasien di Poliklinik Umum Instalasi Rawat Jalan di RS PKU Muhammadiyah Bantul. Hasil ini dibuktikan dengan hasil analisis regresi berganda diperoleh nilai thitung sebesar 8,056 dengan tingkat signifikansi $0,000 \quad(\mathrm{p}<0,05)$, maka hipotesis diterima. Artinya keterlibatan pasien merupakan faktor penting dalam pencapaian loyalitas pasien pada rumah sakit.

Hasil penelitian diketahui keterlibatan pasien yang ada di RS PKU Muhammadiyah Bantul telah dinilai baik oleh responden. Berdasarkan hasil jawaban kuesioner responden didapatkan nilai rerata hitung keterlibatan pasien sebesar 35,41 apabila dibandingkan dengan nilai rerata ideal sebesar 27,00, menunjukkan angka yang lebih besar. Artinya keterlibatan pasien telah dinilai baik oleh pasien.

Keterlibatan pasien mampu mempengaruhi loyalitas pasien dapat dijelaskan karena saat pasien dilibatkan dalam proses pengobatan maka pasien akan merasa mantap menjalani pengobatan di rumah sakit. Melalui keterlibatan pasien, dokter dapat lebih memahami keinginan pasien tentang pengobatan yang akan dijalani, sehingga keputusan yang diambil merupakan hasil kesepakatan antara dokter dengan pasien. Pasien yang dilibatkan secara langsung dalam pengambilan keputusan berkaitan dengan penanganan kesehatan membuat pasien merasa nyaman menjalani setiap prosedur pelayanan kesehatan yang harus dijalankan. Keterlibatan pasien dalam pengambilan keputusan pengobatan membuat pasien menjadi puas dengan pelayanan yang diberikan oleh dokter. ${ }^{2}$ 
Hasil penelitian ini didukung penelitian sebelumnya diperoleh hasil faktor dimensi mutu keterlibatan pasien terbukti berhubungan secara signifikan dengan persepsi pasien mengenai mutu pelayanan dokter rawat jalan. ${ }^{6}$ Pasien yang dilibatkan dalam proses pengobatan semakin mantap dan percaya terhadap pelayanan kesehatan di rumah sakit. Keterlibatan yang dilakukan oleh dokter membuat pasien merasa diakui keberadaannya dan dipercaya oleh dokter dalam perawatan sakitnya. ${ }^{2}$ Hal ini dapat menumbuhkan kepuasan yang merupakan dasar munculnya loyalitas pasien.

\section{SIMPULAN}

Mutu pelayanan dokter pada dimensi keterampilan teknis, hubungan interpersonal, ketersediaan informasi dan keterlibatan pasien secara bersama-sama berpengaruh signifikan terhadap loyalitas pasien di Poliklinik Umum Instalasi Rawat Jalan di RS PKU Muhammadiyah Bantul. Mutu pelayanan dokter pada dimensi keterampilan teknis berpengaruh signifikan terhadap loyalitas pasien di Poliklinik Umum Instalasi Rawat Jalan di RS PKU Muhammadiyah Bantul. Mutu pelayanan dokter pada dimensi hubungan interpersonal berpengaruh signifikan terhadap loyalitas pasien di Poliklinik Umum Instalasi Rawat Jalan di RS PKU Muhammadiyah Bantul. Mutu pelayanan dokter pada dimensi ketersediaan informasi berpengaruh signifikan terhadap loyalitas pasien di Poliklinik Umum Instalasi Rawat Jalan di RS PKU Muhammadiyah Bantul. Mutu pelayanan dokter pada dimensi keterlibatan pasien berpengaruh terhadap loyalitas pasien di Poliklinik Umum Instalasi Rawat Jalan di RS PKU Muhammadiyah Bantul. Berdasarkan simpulan penelitian, saran yang dapat diberikan adalah sebagai berikut:

Dilihat dari faktor dokter mencakup keterampilan teknis, hubungan interpersonal, ketersediaan informasi dan keterlibatan pasien terbukti berpengaruh terhadap loyalitas, maka rumah sakit perlu memperhatikan mutu pelayanan dokter pada dimensi-dimensi tersebut untuk mempertahankan dan meningkatkan loyalitas pasien. Melakukan pengawasan dan evaluasi secara berkala pada pelayanan dokter untuk mempertahankan mutu pelayanan dokter dan selakigus sebagai evaluasi untuk dilakukan perbaikan pada setiap layanan yang kurang maksimal. Memfasilitasi dokter dengan sarana dan prasarana pendukung yang memadai untuk pemberian pelayanan kesehatan secara prima.

\section{DAFTAR PUSTAKA}

1. Kotler, P, 2013, Manajemen Pemasaran. Penerbit Erlangga: Jakarta.

2. Pohan, I, S, 2013, Jaminan Mutu Layanan Kesehatan: Dasar-Dasar Pengertian dan Penerapan. EGC: Jakarta

3. Ariadi, H, 2010, Pengaruh Kualitas Layanan terhadap Kepuasan Pelanggan dalam Membentuk Loyalitas Pelanggan, Tesis, UNDIP: Semarang.

4. Sugiyono, 2008, Metode Penelitian Bisnis, Alfabeta: Bandung.

5. Notoatmodjo, 2005, Metode Penelitian Kesehatan, Rineka Cipta: Jakarta.

6. Selcen, et. al, 2007, Effects Of Service Quality On Customer Satisfaction And Customer Loyalty: Marmara University Hospital, Economics Journal: Özyegin Üniversites.

7. Singh, et. al, 2012, Impact of Perceived Service Quality on Customer Loyalty Intentions in Retail Outlets, European Journal of Business and Management ISSN 2222-1905 (Paper) ISSN 2222-2839, Vol 4, No.21, 2012.

8. Aryani, D, 2005, Pengaruh Kualitas Layanan terhadap Kepuasan Pelanggan dalam Membentuk Loyalitas Pelanggan, Jurnal Ilmu Administrasi dan Organisasi, Mei-Agustus 2010, hlm. 114-126, ISSN 0854-3844 Volume 17, Nomor 2.

9. Griffin, J, 2002, Costumer Loyalty How to Earn It, How To Keep it. Mc-Graw-Hill: Kentucky.

10. Tjiptono, F, 2011, Pemasaran Jasa, Bayumedia Publishing: Jawa Timur. 